\title{
Laparoscopy as a Diagnostic Tool in Ascites of Unknown Origin: A Retrospective Study Conducted at Kasturba Hospital, Manipal
}

\author{
Chetan R Kulkarni ${ }^{1 *}$, Badareesh Laxminarayan ${ }^{2}$ and Annappa Kudva ${ }^{3}$ \\ ${ }^{1}$ Assistant Professor, Department of Surgery, Kasturba Hospital, Manipal \\ ${ }^{2}$ Associate Professor, Department of Surgery, Kasturba Hospital, Manipal \\ ${ }^{3}$ Professor, Department of Surgery, Kasturba Hospital, Manipal \\ Received: February 16, 2018; Published: March 01, 2018 \\ *Corresponding author: Chetan R Kulkarni, Assistant Professor, Department of Surgery, Kasturba Hospital, Manipal, India. Tel: \\ 9535974395;Email: drrmk@rediffmail.com
}

\begin{abstract}
Background: Laparoscopy as a minimally invasive technique has long played an important role in the evaluation of ascites.

Methods: A retrospective analysis was carried out on the record of 80patients who underwent laparoscopy after appropriate investigations had failed to reveal the cause of ascites.

Results: Tuberculous peritonitis was reported in 46(57\%), malignancies in 18(25\%), cirrhosis in 4(5\%) and peritonitis of unknown etiology in $8(10 \%)$ of patients. Two $(2.5 \%)$ patients had complications, an Ileal perforation and in other Incisional hernia.

Conclusion: Laparoscopy was able to diagnose the pathology in $72(90 \%)$ patients with ascites of unknown origin.

Keywords: Ascites; Diagnostic Laparoscopy
\end{abstract}

\section{Introduction}

Laparoscopy, as a minimally invasive technique has developed rapidly in recent years. Endoscopic examination of peritoneal cavity was first attempted in 1901 by George Kelling who termed it as "Celioscopy" $[1,2]$. The term 'ascites' refers to the detectable and pathologic collection of fluid in the peritoneal cavity. Subclinical amount of fluid (i.e. $<1.5$ liter) can be detected using ultrasonography or computed tomography of the abdomen. The important causes of ascites are venous hypertension due to liver cirrhosis, pancreatitis, parasitic infections, tuberculosis, malignancies, lymphomas, chylus ascites, ovarian or peritoneal diseases [3].

Application of diagnostic laparoscopy allows direct visualization of the abdominal-pelvic peritoneum/organs, and may disclose peritoneal deposits of tumor, tuberculosis or disseminated metastatic cancer. Ascitic fluid can be taken for laboratory evaluation as well as biopsy can be taken with direct vision, often adding to the diagnostic accuracy of the procedure [4]. Currently laparoscopy has wide applications and it has made a revolution in gastroenterology, gynecology and urological surgeries [5-7].

This study conducted at Kasturba Hospital, Manipal describes our experience with the diagnostic laparoscopy to determine causes of unexplained ascites that cannot be diagnosed after conventional laboratory examinations (including ascitic fluid cell count, albumin level, total protein level, Gram stain, culture and cytology ) as well as after imaging investigations (including ultrasound and CT scan).

\section{Material and Methods}

The patients of either sex in age group of 15-90 years $(n=80)$, with chief complaints of abdominal pain, distension, fever, vomiting, weight loss and altered bowel habits for variable period who presented between 1st August 2000 and 31st July 2014 for the evaluation of ascites, were included in this study. They failed to reveal the cause after appropriate clinical, laboratory and radiological investigations and underwent diagnostic laparoscopy. Those with obvious renal, cardiac or severe liver disease as to cause jaundice were excluded from the study. All patients were evaluated clinically for signs of chronic liver disease, e.g., palmar erythematic, spider naevi, jaundice, presence of splenomegaly, large collateral veins over abdomen/ back, engorged jugular veins and for presence of enlarged lymph nodes.

All the necessary blood and radiological investigations were carried out depending upon the available facility. They received antibiotics like oral ofloxacin/norfloxacin and intravenous cefriazone/cefotaxime eight hourly in appropriate doses 
perioperatively. Diagnostic laparoscopy was performed under standard general anesthesia with endotracheal intubation. With Karl Storz laparoscope, a $30^{\circ} \mathrm{C} 10 \mathrm{~mm}$ main camera was used with sub-umbilical port. One or two $5 \mathrm{~mm}$ additional ports were used as per surgeons' preference. A retrospective analysis was done on the data collected from the record of 80 patients.

\section{Results}

There were $51 \%(n=41)$ females and $49 \%(n=39)$ males falling in the age groups shown in Figure 1. The presenting complains in the patients were distension of abdomen, pain in abdomen, fever, vomiting, altered bowel habits and weight loss as depicted in Figure 2. The duration of complaints were less than 15days in $27(33.8 \%), 16-30$ days in $24(30 \%), 31-60$ days in $16(20 \%)$ and more than 60 days in $13(16.3 \%)$ patients. On per abdominal examination shifting dullness was present in $53(66.3 \%)$ patients, fluid thrilling $10(12.5 \%)$ patients. $12(15 \%)$ patients had tenderness and 5(6.3\%) patients had shifting dullness with tenderness. The ascites was graded as gross, moderate, mild and flocculated. It was gross in $26(36 \%)$, moderate in $15(23 \%)$, mild in $27(36 \%)$ and flocculated in $4(5 \%)$. All the patients underwent one or other radiological investigations.

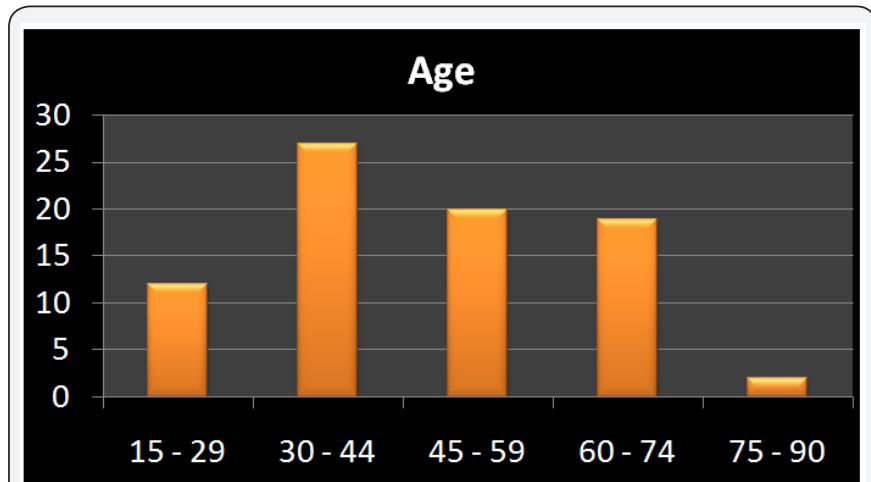

Figure 1: Age distribution of patients.

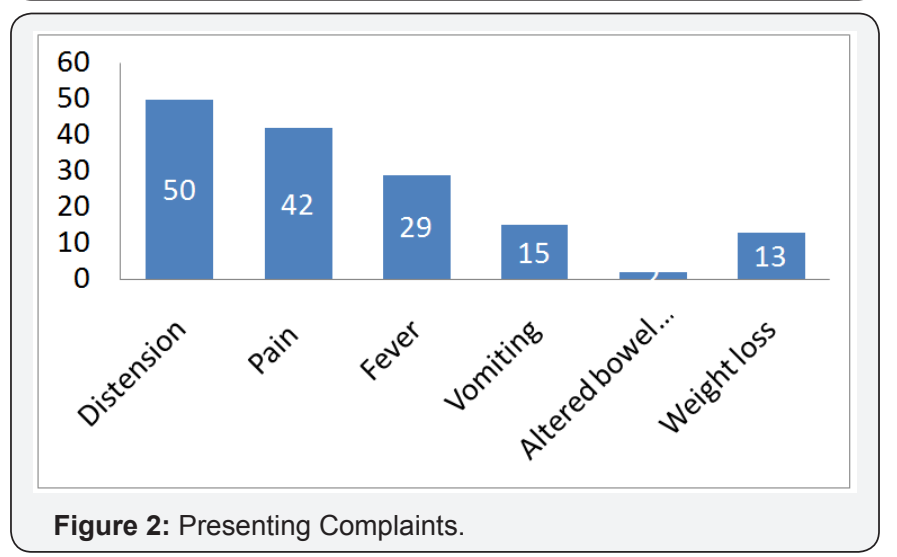

Ultrasonography of abdomen was done in $42(56 \%)$, contrast enhanced computer tomography in $25(36 \%)$ and both in $5(9 \%)$ of patients preoperatively. On laparoscopic visualization peritoneal infiltrates observed in 25(31.3\%), mesenteric infiltration in $14(17.5 \%)$ and of peritoneal, mesenteric and omental involvement seen in $32(40 \%)$ patients. The utility of routine ascetic fluid examination was reviewed in all patients.
The ascitic fluid was transudative in $4(80 \%)$, and exudative in $1(20 \%)$ of patients with cirrhosis of liver. Patients with tuberculosis peritonitis had exudative and transudative ascites in $35(76 \%)$ and $11(24 \%)$ respectively. The ascites in patients with malignant peritonitis was exudative $16(88.8 \%)$ and indeterminate in $2(11.1 \%$ ) (Figure 3 ). There was considerable overlap in the nature of ascites present in the three groups of patients.

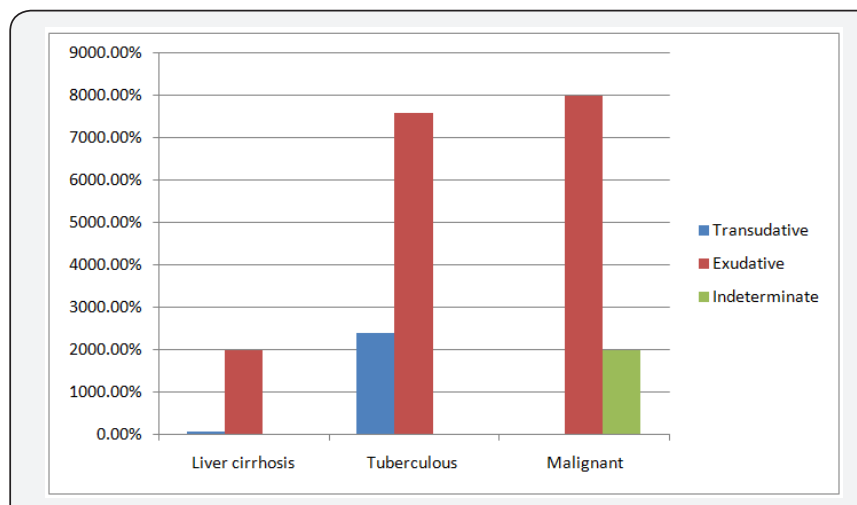

Figure 3: Ascitic fluid analysis.

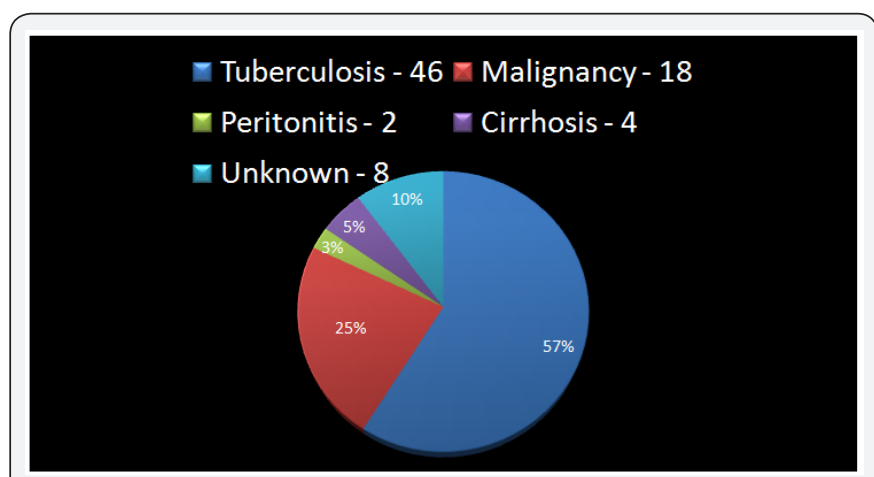

Figure 4: Diagnosis.

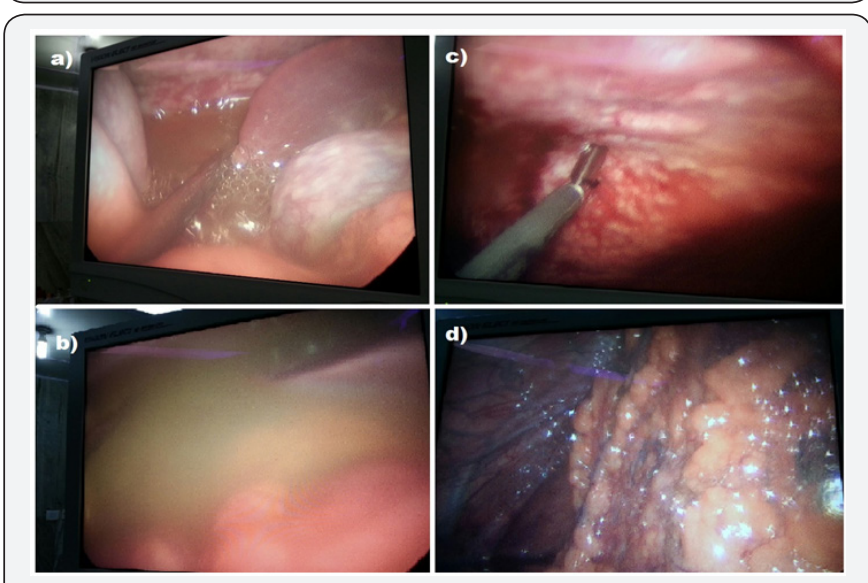

Figure 5: Laparoscopic view.

Following laparoscopy the diagnosis was confirmed on peritoneal fluid cytology and biopsy which was taken laparoscopically. Tuberculosis peritonitis was reported in $46(57 \%)$ of patients, malignancies in $18(25 \%)$, cirrhosis in $4(5 \%)$ and peritonitis of unknown etiology in $8(10 \%)$ of patients (Figure 4). Out of 18 reported cases of malignancies 
the diagnosis was mucinous adenoma in 10(55.6\%), serous adenoma in 6(33.3\%), and peritoneal mesothelioma in $2(11.1 \%)$ cases (Figure 5) depicts the laparoscopic views in a) serous peritonitis, b) infective peritonitis, c) tuberculosis, d) malignant cause. Following laparoscopy on eighty patients the diagnosis was confirmed on peritoneal fluid cytology and biopsy in 72 patients. One patient had complication of laparoscopy as ileal perforation which was diagnosed after 3 days and patient underwent right limited hemicolectomy.

Another patient had late complication of Incisional herniafollowing laparoscopy, which was diagnosed after 6 monthsand patient underwent laparoscopic hernia repair. In our study,laparoscopy was able to diagnose in 72 patients out of 80 givingan accuracy of $90 \%$.

\section{Discussion}

Ascitic fluid may accumulate rapidly or gradually depending upon the cause. In many patients, a diagnosis of liver disease might have been established earlier, as ascites develops later when there is decomposition. Thus, it is important to obtain a history of risk factors for liver disease like alcohol consumption, drug abuse, blood transfusions or hepatitis in the past. Sudden development of ascites in a previously stable patient of cirrhosis should raise the suspicion of hepatoma [8,9]. A history of heart failure and pericardial disease should make one suspect cardiac ascites. A history suggestive of malignancy elsewhere e.g. breast, gastrointestinal tract, ovaries or lymphoma may suggest malignant ascites [10].

In India, tuberculosis as a cause of ascites should be suspected if there is history of fever, constitutional symptoms and in the presence of known extra-abdominal tuberculosis [11]. In patients with pancreatic ascites there is usually a history and the same patient may have more than one disease predisposing to ascites. The diagnosis may be obvious in patients with massive ascites, but when only a small to moderate amount of fluid is present, the accuracy of physical assessment is only about $50 \%$, even by experienced gastroenterologists [12]. Flank dullness which is present in about $90 \%$ of patients, is the most sensitive physical sign. Shifting dullness on percussion is more specific but less sensitive than flank dullness for detection of ascites. Occasionally massive ovarian or hydatid cysts, bowel obstruction and pregnancy with hydramnios can mimicas ascites as they may be associated with fluid thrill.

Analysis of the ascitic fluid is useful in the differential diagnosis of ascites and determining the pathological process [13]. In ascites due to portal hypertension or hypoalbuminaemia, the fluid is clear and straw coloured; turbid ascites may indicate infection. Chylous ascites typically has a milky appearance. Blood stained fluid is usually due to malignancy but may occur with tuberculosis, pancreatitis, hepatic vein thrombosis, recent abdominal punctures or due to a traumatic tap. Dark brown fluid may indicate the presence of bile.
Conventionally low protein ascites with total protein concentration of less than $2.5 \mathrm{~g} / \mathrm{dl}$ is called transudative ascites and usually occurs with portal hypertension or hypoalbuminaemia. An ascites with total protein concentration of more than $2.5 \mathrm{~g} / \mathrm{dl}$ is called exudative ascites. And is usually associated with tuberculosis, malignancy, pancreatitis, myxoedema, etc. The serum-ascites albumin gradient (SAAG) has been found to be superior to the ascites total protein concentration for the differential diagnosis of ascites. The gradient is calculated by subtracting the ascitic fluid albumin level from the serum level obtained on the same day.

Runyon BA et al. [14] described the types of ascites according to the level of serum-ascites albumin gradient [14]. A low gradient of $<1.1 \mathrm{~g} / \mathrm{dl}$ gradient is found in peritoneal tuberculosis, carcinomatosis, biliary ascites and bowel obstruction whereas gradient of more than $1.1 \mathrm{~g} / \mathrm{dl}$ indicates presence of portal hypertension due to liver pathologies with an accuracy of 97 percent. The SAAG also correlates directly with portal pressure [15].

In our study on clinical examination and radiological studies we graded the ascites (gross, moderate, mild, flocculated) and followed the conventional method of ascitic fluid protein estimation and found $154(87.5 \%)$ had high protein (> $2.5 \mathrm{~g} /$ $\mathrm{dL}$ ) ascites. The purpose of this subdivision is to narrow the differential diagnosis of the causes of ascites. However, not infrequently diseases that are believed to cause exclusively exudative ascites may present with transudates and vice versa $[8,9]$. Culture of the ascitic fluid for bacteria should be obtained routinely in patients with cirrhotic ascites, in whom spontaneous bacterial peritonitis (SBP) can occur. For optimal results, 10 $\mathrm{ml}$ of ascitic fluid should be inoculated at the bedside into a blood culture bottle [16]. Gram staining is useful in detecting secondary peritonitis due to gut perforation but is only about 10 percent sensitive in detecting bacteria early in SBP [17].

In tuberculous peritonitis, the smear for acid-fast bacilli (AFB) is rarely positive and culture is positive only in about $50 \%$ of cases [18]. Ascitic fluid glucose can drop significantly in severe infections like secondary peritonitis or late stage of SBP. Low glucose can also be found in malignant ascites. Measurement of ascitic fluid amylase is useful when there is suspicion of pancreatic ascites. Chylous ascites may show Sudan staining fat globules on microscopic examination and increased triglyceride content by chemical examination. Triglyceride levels are low in pseudochylous ascites which can occur due to the presence of large number of degenerating malignant or inflammatory cells. Rarely, fluid may be mucinous in character suggesting pseudomyxoma peritonei [13].

In our study, adenosine deaminase activity (ADA) wasraised in all cases of tuberculosis. However, it was also raisedin 2 patients with malignancy, adding to the confusion. Inother studies, it is found that ADA might be normal in patientssuffering from tuberculosis with liver cirrhosis and might be high in bacterial 
peritonitis $[19,20]$. Radiologic studies are useful in detecting small amount of ascitic fluid as well as helpful in assessing the etiology of ascites [21]. Abdominal sonography may detect as little as $100 \mathrm{ml}$ of intraperitoneal fluid [22]. Although sonography is more cost-effective than computed tomography (CT), but CT detects even smaller amounts of ascitic fluid.

Doppler sonography can detect thrombosis of the portal or hepatic veins. In patients with tuberculous peritonitis, thickening of mesentery and bowel wall, matting of bowel \& Han CL et al. [30]. loops and presence of mesenteric lymph nodes may provide a clue [23]. In patients with small amount of ascites, adhesions from previous surgery or where ascites is compartmentalized, sonography can be an invaluable guide for localizing a safe and useful site for paracentesis. CT may provide information that may be difficult to obtain on ultrasonography. In patients with carcinomatosis or inflammatory peritonitis, a contrast enhanced CT scan may demonstrate enhancement of the peritoneal lining.

Table 1: Information about similar studies done by Luck NH et al. [29]

\begin{tabular}{|c|c|c|}
\hline $\begin{array}{c}\text { Study by Luck NH et al. [29] Role of } \\
\text { laparoscopy in the diagnosis of low serum } \\
\text { ascites albumin gradient }\end{array}$ & $\begin{array}{c}\text { Han CM et al. [30] Diagnostic laparoscopy } \\
\text { in ascites of unknown origin: Chang Gung } \\
\text { Memorial Hospital 20-year experience }\end{array}$ & Kasturba Hospital, Manipal \\
\hline Cirrhosis of liver - $4(12 \%)$ & Cirrhosis - 19(10.8\%) & Cirrhosis- $4(5.6 \%) ;$ \\
\hline Malignant lesion - $7(21.2 \%)$ & Carcinoma to sisperitonie in $99(56.2 \%)$ & Tuberculosis- $40(55.6 \%)$ \\
\hline Granulomatous inflammation - 20(60.6\%) & Tuberculous peritonitis in 31 cases (17.6\%) & Peritonitis-2 (2. 8\%) \\
\hline Budd-Chiare syndrome in -1(3\%) & Miscellaneous causes in $27(15.4 \%)$ & Unknown-8 (11.2\%) \\
\hline
\end{tabular}

Similar results with peritoneal abnormalities have recently been reported for magnetic resonance imaging using gadolinium [24]. In patients with pancreatic ascites alone or associated with liver cirrhosis, endoscopic retrograde pancreatography with fluoroscopy can demonstrate leakage of pancreatic juice from the pancreatic duct. In patients with cirrhosis and large hydrothorax, scintigraphy with Technetium sulfur colloidorradiolabelled albumin can be used to diagnose the intraperitoneal origin of the thoracic fluid. The causes of ascites of unknown origin appear to vary considerably with geographic area and ethnic origin. With the availability of new imaging techniques, the need for laparoscopy in determining the cause of ascites has decreased.

However, if the diagnosis remains unclear, laparoscopy with direct visualization of the peritoneum may be indicated. Typical peritoneal tubercles are found in most patients with tuberculous peritonitis and peritoneal biopsies detect the disease in $74 \%$ of cases [25]. Detection of early primary peritoneal diseases like lesothelioma and mesothelioma by laparoscopy are well reported in literature [26,27]. Laparoscopy has an important role in diagnosing ascites of unknown origin may be cirrhotic or carcinoma peritoneie and indicative in preoperative assessment in staging of gastric, pancreatic or liver cancer. It also plays useful role as therapeutic in hemorrhagic pancreatitis, Chylous ascites and in catheter placement for dialysis. One laparoscopic study from the United States revealed that about $60 \%$ of 51 cases with undiagnosed ascites were shown to have chronic liver disease or intra-abdominal malignancy [9]. Another study from Africa indicated that $40 \%$ of 92 cases with undiagnosed ascites proved to have tuberculous peritonitis [26]. In a retrospective study in 18 patients with abdominal tuberculosis by Tarcoveanu E et al. [28] concluded that diagnostic laparoscopy can be essential and helpful in the management strategy. We have compared our results with the studies done by Luck et al. [29] on diagnostic laparoscopy in 32 patients with low serum ascites albumin gradient and with Han CM et al. [30] at Chang Gung Memorial
Hospital reported 176 diagnostic laparoscopies in patients with unknown cause of ascites as given in Table 1.

Incidence of tuberculous ascites was higher in our study as compared to the study by Luck NH et al. [29] and Han CM et al. [30] whereas incidence of carcinoma to sis peritonie was highest in study by Han CM et al. [30]. In our study in patients with more than one cause of ascites, laparoscopy was particularly helpful. In one patient with known liver cirrhosis, laparoscopy and biopsy showed ascites to be due to tuberculosis. Another patient with papillary serous cystadenoma, ascites was due to tuberculosis and in one patient it was observed to have liver cirrhosis with serous cyst adenocarcinoma of ovary. Out of 8 unknown cases, 1 patient was later diagnosed of having systemic lupus erythematosis. In 4 patients, laparoscopy was not possible due to dense adhesions and in 3 patients, because remained obscure. One complication was encountered during the laparoscopy. Spontaneous bacterial peritonitis is an important complication in patients with ascites and following diagnostic laparoscopy.

However with adequate prophylaxis with antibiotics in preoperative period the risk of morbidity and mortality can be minimized. No fatality observed in our study due to bacterial peritonitis. The findings in our study indicate that abdominal laparoscopy is a safe, quick and inexpensive diagnostic tool particularly when appropriate and adequate tissue is taken for pathological examination. On Laparoscopy accurate diagnosis of the cause of ascites was possible in $90 \%$ of the patients.

\section{Conclusion}

To conclude, laparoscopy is a valuable means of assessing the peritoneal cavity in patients with un-explained ascites when the primary cause remains unclear. With a careful and standardized technique of entry, complications are rare, the diagnosis can be accurately made with selective biopsy specimens and appropriate treatment can then be instituted without delay. 


\section{Open Access Journal of Surgery}

\section{References}

1. Spaner SJ, Warnock GL (1997) A brief history of endoscopy, laparoscopy, and laparoscopic surgery. J Laparoendosc Adv Surg Tech A 7(6): 369-373.

2. Neudecker J, Sauerland S, Neugebauer E, Bergamaschi R, Bonjer HJ, et al. (2002) The European Association for Endoscopic Surgery clinical practice guideline on the pneumoperitoneum for laparoscopic surgery. Surg Endosc 16: 1121-1143.

3. McIntyre N, Burroughs AK (1996) Cirrhosis, portal hypertension and Ascites. In: Weatherall DJ, et al. (Eds.), Oxford Textbook of Medicine ( $3^{\text {rd }}$ edn), Oxford University Press, India, pp: 2085-2100.

4. Inadomi JM, Kapur S, Kinkhabwala M, Cello JP (2001) The laparoscopic evaluation of ascites. Gastrointest Endosc Clin N Am 11: 79-91.

5. Gurusamy KS, Vaughan J, Davidson BR (2014) Low pressure versus standard pressure pneumoperitoneum in laparoscopic cholecystectomy. Cochrane Database Syst Rev (2): CD006930.

6. Hasson HM, Rotman C, Rana N, Kumari NA (2000) Open laparoscopy: 29-year experience. Obstet Gynecol 96(5 Pt 1): 763-766.

7. Ost MC, Tan BJ, Lee BR (2005) Urological laparoscopy: basic physiological considerations and immunological consequences. J Uro 174(4 Pt 1): 1183-1188

8. Moore K (2003) Cirrhosis, portal hypertension, and ascites. In: Warrell DA, et al. (Eds.), Oxford Text book of Medicine, $\left(4^{\text {th }}\right.$ edn) Volume 2, Oxford University Press, New York, USA, pp: 733-741.

9. Gines P, Cardenas A, Arroyo V, Rodes J (2004) Management of cirrhosis and ascites. N Engl J Med 350: 1646-1654.

10. Runyon BA, Hoefs JC, Morgan TR (1988) Ascitic fluid analysis in malignancy related ascites. Hepatology 8(5): 1104-1109.

11. Ali Uzunkoy, Muge Harma, Mehmet Harma (2004) Diagnosis of abdominal tuberculos: Experience from 11 cases and review of the literature. World J Gastroenterol 10(24): 3647-3649.

12. Cattau EL, Benjamin SB, Knuff TE, Castell DO (1982) The accuracy of the physical examination in the diagnosis of suspected ascites. JAMA 247(8): 1164-1166.

13. Runyon BA (1991) Paracentesis and ascitic fluid analysis. In: Yamada T, et al. (Eds.), Text book of Gastroenterology, JB Lippincott, New York, USA, pp: 2455-2465.

14. Runyon BA, Montano AA, Akriviadis EA (1992) The SAAG is superior to exudate-transudate concept in differential diagnosis of ascites. Ann Intern Med 117: 215-220.

15. Hoefs JC (1983) Serum protein concentration and portal pressure determine the ascitic fluid protein concentration in patients with chronic liver disease. J Lab Clin Med 102: 260-273.

This work is licensed under Creative

Commons Attribution 4.0 Licens

DOI: 10.19080/OAJS.2018.08.555740
16. Runyon BA, Antillon MR, Akriviadis EA, Mc Huchison JG (1990) Bedside inoculation of blood culture bottles with ascitic fluid is superior to delayed inoculation in the detection of spontaneous bacterial peritonitis. J Clin Micro biol 28(12): 2811-2812.

17. Akriviadis EA, Runyon BA (1990) Utility of an algorithm in differentiating spontaneous from secondary bacterial peritonitis. Gastroenterology 98(1): 127-133.

18. Karney WW, O’Donoghue JM, Ostrow JH, Holmes KK, Beaty HN (1977) The spectrum of tuberculous peritonitis. Chest 72(3): 310-315.

19. Voigt MD, Kalvaria I, Berman P, Lombard C, Kirsh RE, et al. (1989) Diagnostic value of ascites adenosine deaminase in tuberculous peritonitis. Lancet 1(8641): 751-754.

20. Banales JL, Rivera-Martinez E, Perez-Gonzalez L, Selman M, Raymond Y, et al. (1999) Evaluation of adenosine deaminase activity in the Mycobacterium tuberculos culture supernatants. Arch Med Res 30(5): 358-359.

21. Theoni RF (1995) The role of imaging in patients with ascites. Am J Roentgenol 165(1): 16-18.

22. Goldberg BB, Goodman GA, Clearfield HR (1970) Evaluation of ascites by ultrasound. Radiology 96(1): 15-22.

23. Jain R, Sawhney S, Bhargava DK, Berry M (1995) Diagnosis of abdominal tuberculos: sonographic findings in patients with early tuberculos. AJR Am J Roentgenol 165(6): 1391-1395.

24. Low RN, Sigeti JS (1994) MR imaging of peritoneal disease: comparison of contrast-enhanced fast multi planar spoiled gradient-recalled and spin-echo imaging. AJR Am J Roentgenol 163(5): 1131-1140.

25. Manohar A, Simjee AE, Haffejee AA, Pettengell KE (1990) Symptoms and investigative findings in 145 patients with tuberculous peritonitis diagnosed by peritoneoscopy and biopsy over a five year period. Gut 31(10): 1130-1132.

26. Menzies RI, Fitzgerald JM, Mulpeter K (1985) Laparoscopic diagnosis of ascites in Lesotho. Br Med J (Clin Res Ed) 291(6498): 473-475.

27. Sugarbaker PH, Yan H, Grazi RV, Shmookler BM (2000) Early localized peritoneal mesothelioma as an incidental find in gat laparoscopy. Report of a case and implications regarding natural history of the disease. Cancer 89(6): 1279-1284.

28. Tarcoveanu E, Diofte G, Bradea C, Lupascu C, Moldovanu R, et al. (2009) Peritoneal Tuberculos in Laparoscopic era. Acta Chir Belg 109(1): 65-70.

29. Luck NH, Khan AA, Alam A, Butt AK, Shafquat F (2007) Role of laparoscopy in the diagnosis of low serum ascites albumin gradiant. J Pak Med Assoc 57(1): 33-34

30. Han CM, Lee CL, Huang KG, Chu CM, Lin SM, et al. (2008) Diagnostic laparoscopy in ascites of unknown origin: Chang Gung Memorial Hospital 20-year experience. Chang Gung Med J 31(4): 378-383.

\section{Your next submission with Juniper Publishers} will reach you the below assets

- Quality Editorial service

- Swift Peer Review

- Reprints availability

- E-prints Service

- Manuscript Podcast for convenient understanding

- Global attainment for your research

- Manuscript accessibility in different formats

( Pdf, E-pub, Full Text, Audio)

- Unceasing customer service

Track the below URL for one-step submission https://juniperpublishers.com/online-submission.php 